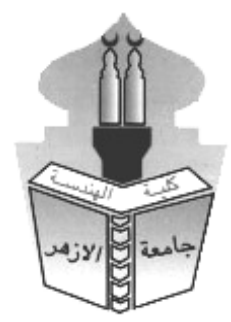

\title{
EFFECT OF FRICTION STIR WELDING PARAMETERS ON MICROSTRUCTURAL CHARACTERISTICS AND CORROSION BEHAVIOR OF AA7020-O BASED ON TAGUCHI DOE APPROACH
}

\author{
M. S. Gad ${ }^{1}$ and S.S. Mohamed ${ }^{2}$ \\ ${ }^{1}$ Industrial Engineering and Production Technology Department, Modern Academy for \\ Engineering and Technology, Cairo, Egypt. \\ ${ }^{2}$ Mechanical Engineering Department, Shoubra Faculty of Engineering, Benha University, \\ Cairo, Egypt.
}

\begin{abstract}
In the present study, Taguchi approach for experiment design was utilized, through an orthogonal array of $\mathrm{L}_{9}\left(3^{3}\right)$, to investigate the effect of friction stir welding (FSW) process parameters, and post weld heat treatment (PWHT) on the microstructural characteristics and corrosion behavior of the nugget zone (NZ) of the FS welded joints and the base metal (BM) samples of AA7020-O. Microstructural characteristics were investigated through grains size (GS) and aspect ratio (AR) of $\alpha$-Al grains. Corrosion behavior was studied by potentiodynamic polarization test and static immersion in $3.5 \% \mathrm{NaCl}$ solution at room temperature. Results of analysis of variance (ANOVA) revealed that, the GS at center of the NZ is directly statistically significant affected by increasing the tool rotational speed and by changing the PWHT state from the as weld (AW) state to T4 or T6 tempers, while, the AS is directly statistically significant affected by increasing the tool rotational speed, and, it is inversely statistically significant affected by increasing the welding speed. Moreover, the corrosion rate (CR) is found to be directly statistically significant affected by changing the PWHT state from the AW state to T4 or T6 tempers, while, it is inversely statistically significant affected by increasing the tool rotational speed. Nevertheless, As compared to BM samples, FSW has highly decreased the CR in the NZ, for T4 and T6 tempers, while it is of comparable values in $\mathrm{AW}$ state. The percentage contribution $\left(\mathrm{P}_{\mathrm{C}}\right)$ of each factor is also determined.

Key words: FSW, Processing Parameters, PWHT, Taguchi, Microstructure, Corrosion Behavior, Potentiodynamic Polarization, Corrosion Rate.
\end{abstract}

\section{INTRODUCTION}

The growing interest in FSW is subjective of its ability to weld materials which was considered non weldable or of a poor weldability, and also, of the better properties of the welded joints over that of the traditional fusion welding techniques[1-5]. Involvement of aluminum alloy (AA)s in wide spreading manufacturing branches, has allowed FSW technique to be a versatile choice for routine Al parts welding operations[6]. AAs are becoming more preferable in the shipbuilding industry; as they decrease the weight of the ship structure compared to steel structures. A large volume to weight ratio increase the ability to load ships by more shipments weight for the same ship sink depth, or to increase the ship travel speed. The copper-free alloys of 7xxx series exhibit good resistance to general corrosion approaching that of the wrought $3 \times x x, 5 \times x x$, and 6xxx alloys[7-9]. AA7020 is the most widely used copperfree alloy in the 7xxx series in different fields such as transport, the mechanics industry, and armaments. Usually, the FS welded joints are used in the AW condition when BM is in the hardened conditions (T6 and T4 tempers). However, there are some advantages in conducting 
the FSW of AA workpieces in soft state compared to other hardened states. Then, it is necessary to conduct PWHT to strengthen the component [1, 10-14].

Process parameters and PWHT have important effects on the welded joint material properties, such as the metallurgical microstructure, and corrosion resistivity, [4, 15, 16]. Therefore, they have to be carefully selected and investigated.

Golezani et al.[3], have analyzed the microstructure of 4mm thickness AA7020-T6 FS welded at different tool rotational speeds. The results showed that lower rotational speeds results in finer grain structure and larger secondary phase particles in the stirred zone (SZ) of the joints, where, the size and value of density of the second phase particles were similar to those of the BM. While, higher tool rotational speeds resulted in finer second phase particles with higher value of density. Ilkhichi et al.[4], have applied response surface methodology in conjunction with a central composite design of experiment to predict the GS of FS welded AA 7020 joints with the variation of tool rotational speed, traverse speed, and tool axial force. The ANOVA of the results revealed that the average GS of the NZ of the joints increased with increase of rotational speed and axial force, but decreased with increase of traverse speed. Mahmoud et al.[17], have investigated microstructural characteristics of FS welded AA7020$\mathrm{O}$ plates, while the tool rotational and welding speeds were the main varying parameters. Microstructures of the central portion of the NZs of samples FS welded showed that the grains of the $\alpha$-Al phase have equiaxed shape, and that, the GS depends significantly on tool rotational speed. It was clear that at constant traverse speed, increasing the tool rotational speed increases the average size of the $\alpha$-Al primary phase. This was attributed to the increase in heat input and slower cooling rate in the NZs. Furthermore, results showed that there are several precipitates such as $\mathrm{Al}_{2} \mathrm{O}_{3}$ were formed at the center of the NZ, and tend to precipitate at grain boundaries of $\alpha$-Al, Also.

Other investigations $[18,19]$ have related the corrosion severity with the size and density of intermetallics and intergranular precipitation, especially when the predominant corrosion mechanism is pitting corrosion. Where coarse precipitates of high density increase the galvanic corrosion, resulting in a highly localized pitting corrosion and hence, increase the CR. While fine precipitates result in homogenous pitting corrosion.

The aim of the present investigation is to assess the effect of FSW tool rotational speed and welding speed, as well as, the PWHT on the microstructure characteristics and corrosion behavior of AA7020 through utilization of the optimum number of experiment trials.

\section{EXPERIMENTAL PROCEDURES}

In this study, Rolled AA7020 Al alloy plates, with the chemical composition shown in Table 1 , of $10 \mathrm{~mm}$ thickness was used and cut to dimensions of $150 \mathrm{~mm}$ (length) $\times 50 \mathrm{~mm}$ (width). All samples were pre-weld annealed (O-temper). Pairs of AA7020-O samples were welded together using FSW tool made of K110 tool steel and with dimensions shown in Figure 1. With clockwise direction of the tool rotation, the thread of the tool pin applied a downward pushing force on the plasticized material and enhances vertical material flow during welding[20]. Welding was conducted in a direction perpendicular to the rolling direction as shown in Figure 2. Downward force was kept constant by maintaining constant tool shoulder sink depth of $0.1 \mathrm{~mm}$.

Table 1: Chemical composition of AA7020 undergoing study

\begin{tabular}{|l|l|l|l|l|l|l|l|l|l|}
\hline Constituent & $\mathrm{Si}$ & $\mathrm{Mn}$ & $\mathrm{Mg}$ & $\mathrm{Zn}$ & $\mathrm{Cr}$ & $\mathrm{Ti}$ & $\mathrm{Fe}$ & $\mathrm{V}$ & Al \\
\hline Weight (\%) & $\mathbf{0 . 0 3 3 5}$ & $\mathbf{0 . 1 9}$ & $\mathbf{0 . 9 8 6}$ & $\mathbf{4 . 2 6}$ & $\mathbf{2 . 8 3}$ & $\mathbf{0 . 0 0 8 8}$ & $\mathbf{0 . 0 1 0 9}$ & $\mathbf{0 . 0 0 7 4}$ & Balance \\
\hline
\end{tabular}



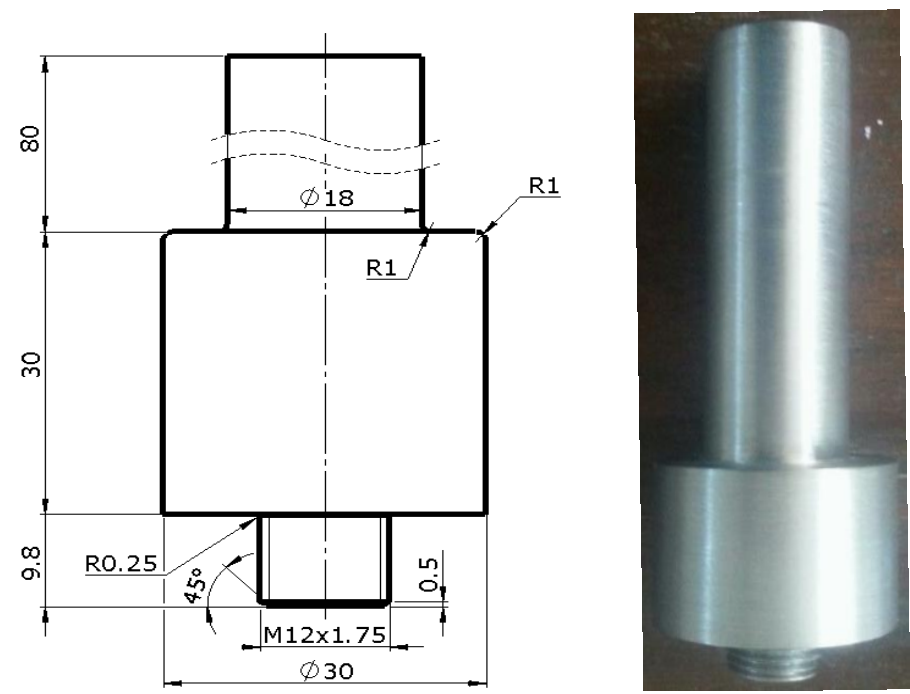

Figure 1: Welding tool dimensions (mm)

Using the combination of levels for each control factor as indicated in

Table $\mathbf{2}$, when applying experiment randomization for three independent variables each of three levels, an orthogonal array of $\mathrm{L}_{9}\left(3^{3}\right)$ which has 8 degrees of freedom was used. A total of nine experimental runs were conducted, as listed in Table 3 ,

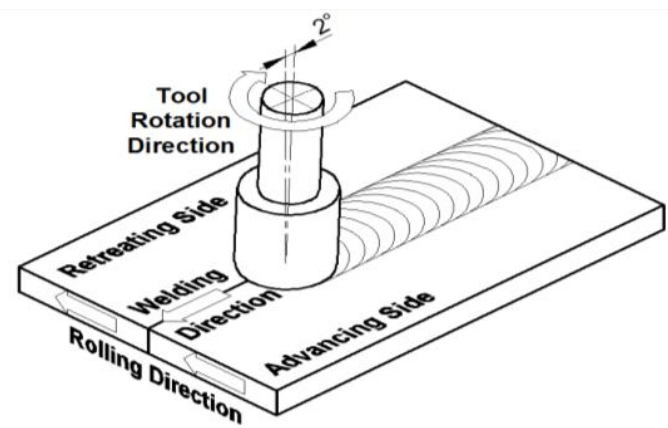

Figure 2: Welding Process.

After welding the samples, the welded samples were divided into three groups with two material HT states, solution heat treated and naturally aged to a substantially stable conditions state (T4), solution heat treated and artificially aged [21] state (T6), and the third group was kept at the AW state. Solution HT was performed at temperature $450 \pm 5^{\circ} \mathrm{C}$ [10]. The samples were soaked for 5 hours in the furnace [21], and then quenched in water at room temperature with a quench delay 15 seconds. Precipitation hardening for the T4-condition samples was achieved by natural ageing at room temperature for more than 30 days to reach a stable condition[5]. For the T6-condition samples, precipitation hardening was achieved by artificial ageing at $165 \pm 5^{\circ} \mathrm{C}$ for 10 hours to obtain optimum strength as reported by Wojcirch[18].

Table 2: Experiment design matrix

\begin{tabular}{|c|c|c|c|}
\hline \multirow{2}{*}{ Control Factor } & \multicolumn{3}{|c|}{$\begin{array}{c}\text { Level } \\
\text { Medium }\end{array}$} \\
\cline { 2 - 4 } & How \\
\hline $\begin{array}{c}\text { tool rotational } \\
\text { speed (rpm) }\end{array}$ & 315 & $\mathbf{0}$ & $(+1)$ \\
\hline $\begin{array}{c}\text { welding speed } \\
(\mathrm{mm} / \mathrm{min})\end{array}$ & 25 & 31.5 & $\mathbf{4 0 0}$ \\
\hline PWHT & AW & T4 & T6 \\
\hline
\end{tabular}


Table 3: Experiment trials

\begin{tabular}{|c|c|c|c|}
\cline { 2 - 4 } \multicolumn{1}{c|}{} & \multicolumn{3}{c|}{ Control Factor } \\
\hline $\begin{array}{c}\text { Trial } \\
\text { No. and } \\
\text { sample } \\
\text { code }\end{array}$ & $\begin{array}{c}\text { Tool } \\
\text { Rotational } \\
\text { Speed } \\
(\mathrm{rpm})\end{array}$ & $\begin{array}{c}\text { Welding } \\
\text { Speed } \\
(\mathrm{mm} / \mathrm{min})\end{array}$ & PWHT \\
\hline 1 & 315 & 25 & $\mathrm{AW}$ \\
\hline 4 & 315 & 31.5 & $\mathrm{~T} 4$ \\
\hline 7 & 315 & 40 & $\mathrm{~T} 6$ \\
\hline 5 & 500 & 25 & $\mathrm{~T} 4$ \\
\hline 8 & 500 & 31.5 & $\mathrm{~T} 6$ \\
\hline 2 & 500 & 40 & $\mathrm{AW}$ \\
\hline 9 & 800 & 25 & $\mathrm{~T} 6$ \\
\hline 3 & 800 & 31.5 & $\mathrm{AW}$ \\
\hline 6 & 800 & 40 & $\mathrm{~T} 4$ \\
\hline
\end{tabular}

A sample from each experiment trial was cut for microstructure investigation. Surfaces perpendicular to the welding direction was wet grounded using $\mathrm{SiC}$ abrasive papers up to P2000, and polished using $0.3 \mu \mathrm{m}$ liquid alumina on a $1 \mu \mathrm{m}$ flocked polishing cloth. Microetching was carried out by immersing the polished surface in $1 \mathrm{ml} \mathrm{HF}, 1.5 \mathrm{ml} \mathrm{HCl}, 2.5 \mathrm{ml}$ $\mathrm{HNO}_{3}$, and $95 \mathrm{ml} \mathrm{H} \mathrm{H}_{2} \mathrm{O}$ for 90 seconds, and then cleaned by distilled water. An Olympus optical microscope was used to observe the microstructure. GS and AS were measured using $J M i$ croVision computer software.

Two other samples were cut from each experiment trial at the NZ and from the BM with different HT (O, T4, and T6); one was used for static immersion and the other for potentiodynamic test. Samples were marked by engraved numbers, wet grounded using $\mathrm{SiC}$ abrasive papers, cleaned with methyl alcohol and distilled water, and dried with hot air. Static immersion samples were immersed in $3.5 \% \mathrm{NaCl}$ solution for $360 \mathrm{hr}$, then cleaned with distilled water and ultrasonic vibrator, and dried with hot air for SEM investigation and EDX analysis. Potentiodynamic test samples' surfaces were masked with epoxy resin while the NZs of a known area were kept unmasked. The electrochemical cell used consisted of standard $\mathrm{Ag} / \mathrm{AgCl}$ reference electrode, Platinum counter electrode, and the sample as the working electrode. Potentiodynamic tests were carried out with a scan range from $-1.8 \mathrm{~V}$ to $1.5 \mathrm{~V}$ and a scan rate of $1 \mathrm{mV} / \mathrm{s}$ using Autolap $302 \mathrm{~N}$ potentiostat/galvanostat workstation. Using Tafel plots, the corrosion potential (Ecorr), the Tafel constants for anode $(\beta \mathrm{a})$, and for cathode $(\beta \mathrm{c})$ were determined. $i_{\text {corr }}$ was estimated using Tafel extrapolation with computer software.

\section{RESULTS AND DISCUSSION}

\subsection{Microstructure characteristics}

Figure 3 shows optical micrographs of BM samples in different HT states. In all HT states the microstructure shows no change from a typically rolled grain structure. The grains were extremely elongated in the rolling direction and precipitates are commonly diffused in the longitudinal rolling direction. BM-O shows slight diffusion of thin second phase lines which is diffused during the annealing process. For BM-T4, natural ageing has reached a satisfactory level of precipitation, as the microstructure shows very fine precipitates dispersed in the Al matrix in an even structure of linear arrays. BM-T6 microstructure showed a clear change in formation of the second phase precipitates, large amounts of thick precipitates lines in the Al matrix. For all BM HT states, it was not possible to determine the GS of the extremely elongated grains. The grain boundaries could not be resolved as the grains form a banded structure typical of material having undergone a rolling operation. A similar banded structure and hard resolution of the grains was also reported by Krishnan for AA6061 Al alloy[13]. 


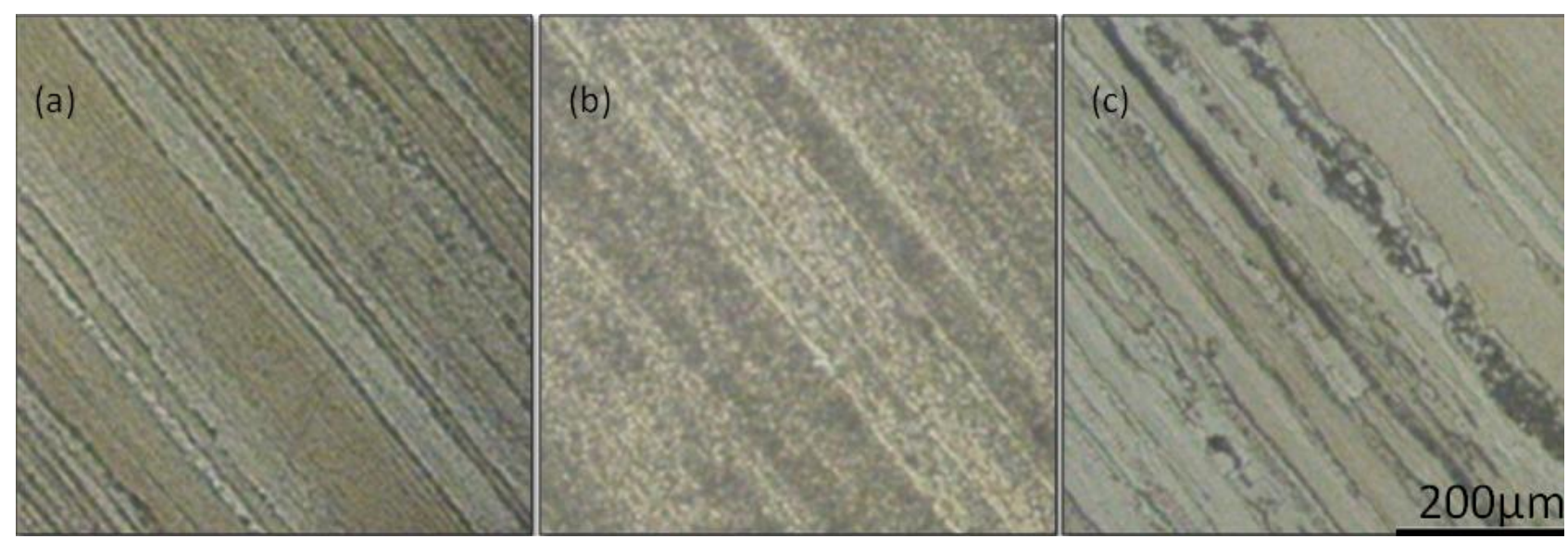

Figure 3: Optical micrographs of BM samples in (a) $O$ temper, (b) T4 temper, and (c) T6 temper NZs' microstructures, shown in Figure 5, have shown complete transformation of the grain structure from the longitudinally elongated grains into finer equiaxed grains. This transformation was discussed by many researchers [22-24] and it is a stable believe that it happens due to material subjection to sever heat and plastic deformation resulting from the nature of the welding process at the NZ. Where dynamic recrystallization of the grains is the most recognized mechanism forms the grain structure in the NZ [4, 15, 25]. As for the precipitates size and distribution, samples 1,2, and 3 (left in the AW state) have small precipitates with low density. This can be attributed to partial dissolution of the precipitates during FSW as reported by Jata et al.[1]. The PWHT is appearing to have nearly the same effect to NZ as how the HT affected the BM, in terms of precipitates state. For samples 4,5 , and 6 (PWH treated to T4 state), second phase precipitates were present in a higher density with lager size compared to samples left in the AW state. For samples 7, 8, and 9 (PWH treated to T6 state), coarse precipitates were also dispersed all over the NZ.

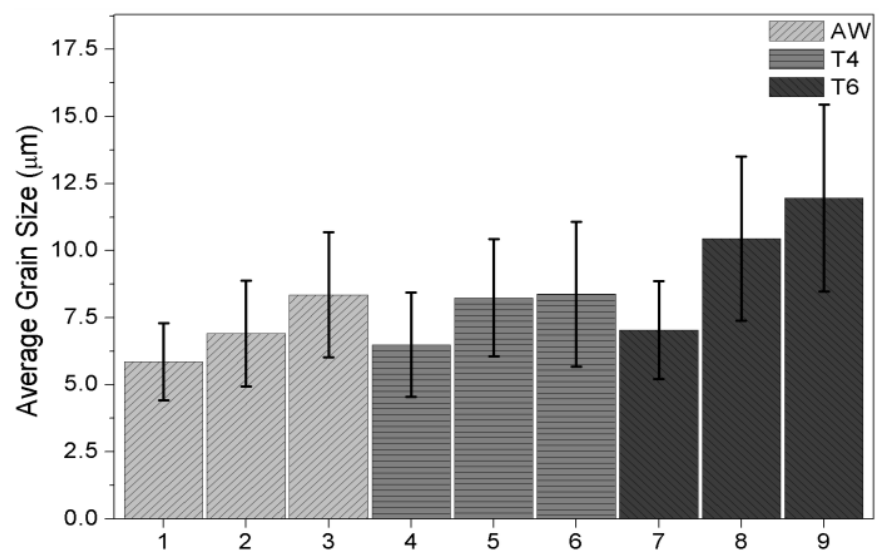

Figure 4: Average GS at the NZ center of samples FS welded and PWHT with conditions listed in Table 3. 3: Experiment trials

GS of NZ is believed to be affected mainly by the rate of plastic deformation resulting from the relative tool movement, with an inverse relation, and the heat input with a direct relation[3]. Average GS at the center of the NZs, as well as, its standard deviation is shown in Figure 4. Figure 6 shows the main effects on the average GS at the center of the NZ. It can be seen that, increasing the tool rotational speed results in an increase of the average GS. This is attributed to the increase in the heat input during FSW and its predominance over the rate of plastic deformation. Also, the average GS is having an inversely proportional relation with the welding speed. Changing the material state, after welding process, from the AW state to T4 temper or T6 temper increase the average GS. This grain growth after PWHT was also reported by Mosleh et al.[12]. 

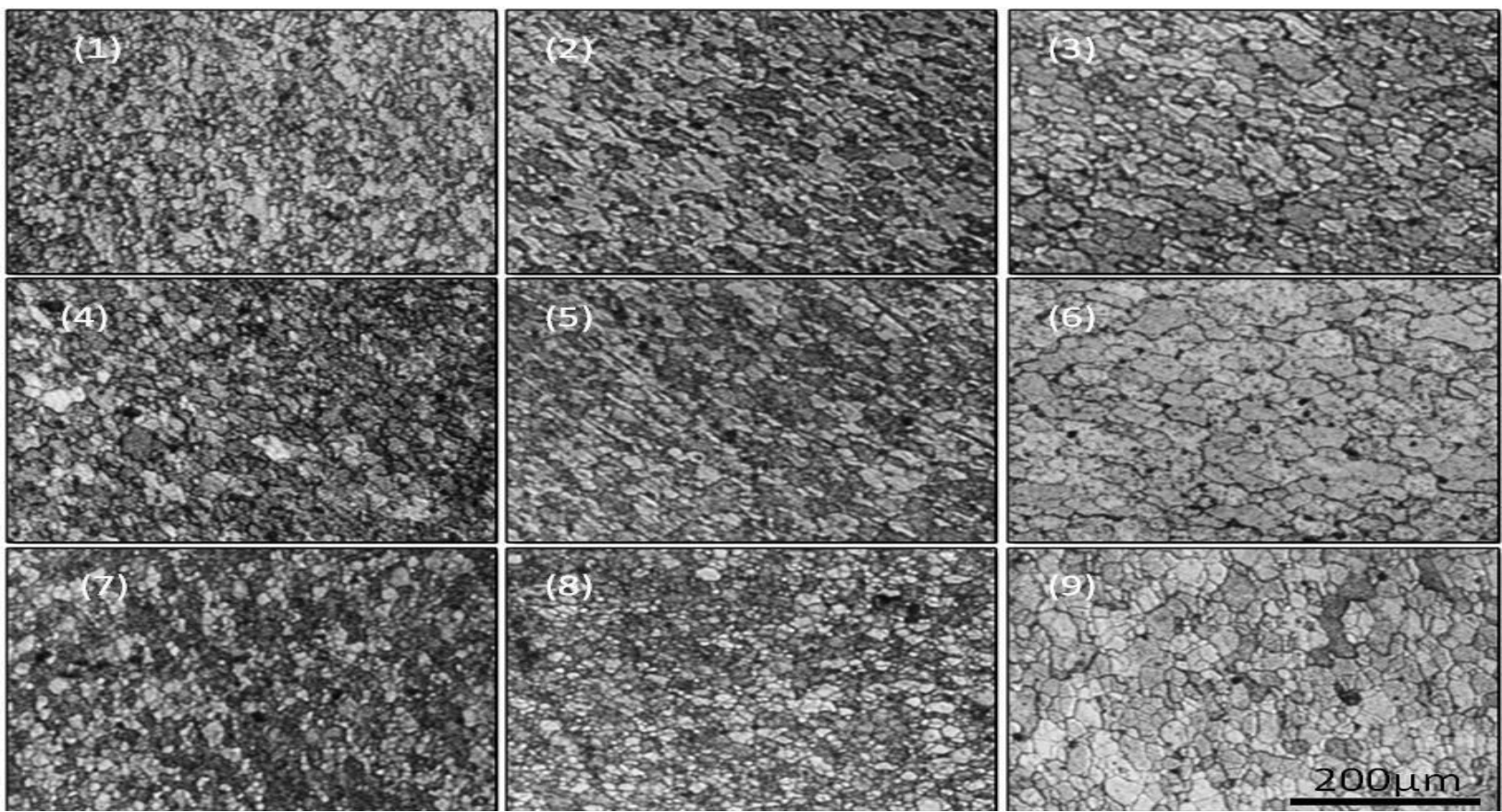

Figure 5: Optical micrographs of samples' NZs, FS welded and PWHT with conditions listed in Table 3.

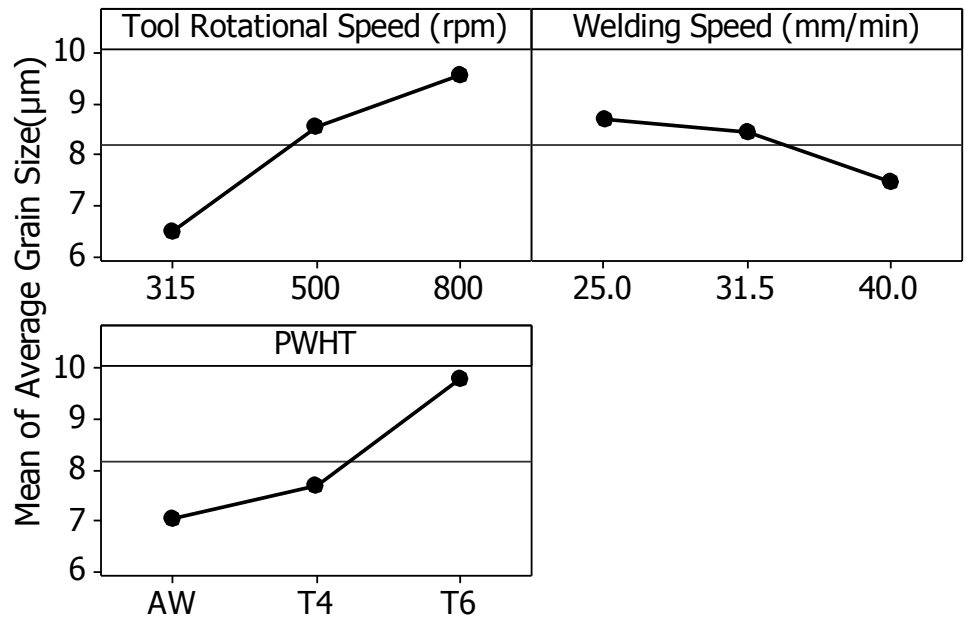

Figure 6: Plot of factors effects on average GS at the NZ center.

For a confidence level of $95 \%$, statistical Significance $(\mathrm{P})$ values which are less than 0.05 indicate that null hypothesis should be rejected and thus the effect of the respective factor is significant. It can be seen from the ANOVA results listed in that the tool rotational speed $(\mathrm{P}=0.033)$, and the PWHT $(\mathrm{P}=0.039)$ are the statistically significant affecting factors on the GS. Where, the tool rotational speed has the most significant impact on average GS followed by the PWHT. In addition, the effect of welding speed $(\mathrm{P}=0.164)$ is not statistically significant.

Table 4: The ANOVA results for average GS of the center region of the NZs

\begin{tabular}{|l|c|c|c|c|c|c|}
\hline Source & DOF & SS & MS & F & P & P $_{\text {C }}(\%)$ \\
\hline Tool Rotational Speed (rpm) & 2 & 14.9608 & 7.4804 & 29.58 & $\mathbf{0 . 0 3 3}$ & $\mathbf{4 8 . 8 3}$ \\
\hline Welding Speed (mm/min) & 2 & 2.5803 & 1.2901 & $\mathbf{5 . 1 0}$ & $\mathbf{0 . 1 6 4}$ & $\mathbf{8 . 4 1}$ \\
\hline PWHT & 2 & $\mathbf{1 2 . 5 9 9 4}$ & $\mathbf{6 . 2 9 9 7}$ & $\mathbf{2 4 . 9 1}$ & $\mathbf{0 . 0 3 9}$ & $\mathbf{4 1 . 1 1}$ \\
\hline Residual Error & 2 & $\mathbf{0 . 5 0 5 8}$ & $\mathbf{0 . 2 5 2 9}$ & & & $\mathbf{1 . 6 5}$ \\
\hline Total & $\mathbf{8}$ & $\mathbf{3 0 . 6 4 6 3}$ & & & & $\mathbf{1 0 0}$ \\
\hline
\end{tabular}

SS, sum of squares; MS, mean square; F, F-test value

The degree of the grains transformation from the extremely elongated shape to an equiaxed shape during FSW at the NZ can be assessed using the value of the grains AR which is calculated as the grain width over the grain length. A perfectly equiaxed grain will have an AR of 1, while, elongated grains will have a smaller value of fractions. Average AR at the center of the NZs, as well as, its standard deviation is shown in Figure 7. 
Figure 8 shows the main effects on the average AR at the center of the NZ. It can be seen that, increasing the tool rotational speed results in an increase of the grain's AR. Also, the grain's $\mathrm{AR}$ is having an inversely proportional relation with the welding speed. Changing the material state, after welding process, from the AW state to T4 temper or T6 temper has a minor effect on the grain's AR as it slightly increased over the mean value in the case of T4 temper and slightly decreased under the mean value in the case of T6 temper.

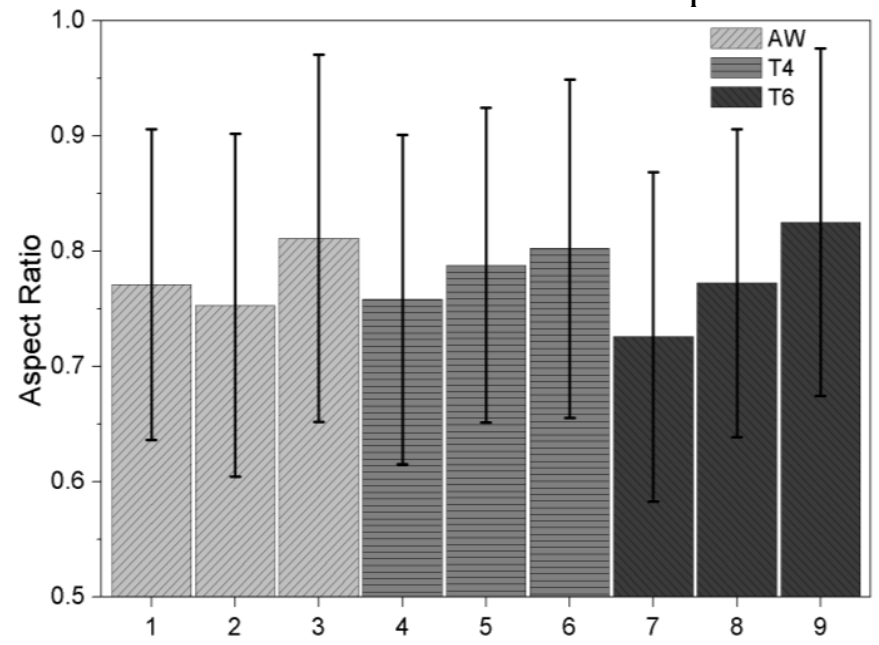

Figure 7: Average grains AR at the NZ center of samples FS welded and PWHT with conditions listed in Table 3. 3: Experiment trials

It can be seen from Table 5 that the tool rotational speed $(\mathrm{P}=0.013)$, and the welding speed $(\mathrm{P}=0.040)$ are the statistically significant affecting factors on the grain's AR. Where, the tool rotational speed has the most significant impact on average AR followed by the welding speed. In addition, the effect of PWHT $(\mathrm{P}=0.416)$ is not statistically significant.

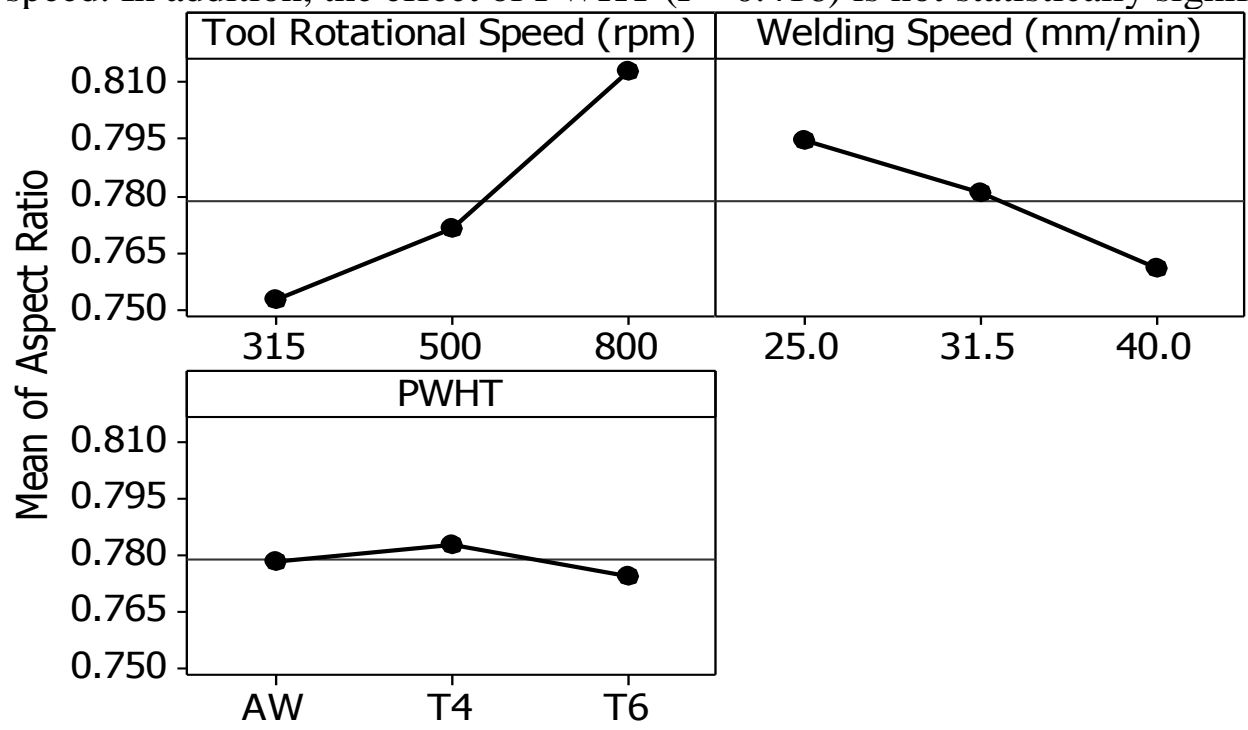

Figure 8: Plot of factors effects on average $A R$ at the $N Z$ center

Table 5: The ANOVA results for grains AR of the center region of the NZs

\begin{tabular}{|l|c|c|c|c|c|c|}
\hline Source & DOF & SS & MS & F & P & PC (\%) \\
\hline Tool Rotational Speed (rpm) & 2 & 0.0059 & 0.0029 & 78.74 & 0.013 & 74.85 \\
\hline Welding Speed (mm/min) & 2 & 0.0018 & 0.0009 & 24.06 & 0.040 & 22.87 \\
\hline PWHT & 2 & 0.0001 & 0.0001 & 1.40 & 0.416 & 1.33 \\
\hline Residual Error & 2 & 0.0001 & 0.0000 & & & 0.95 \\
\hline Total & 8 & 0.0078 & & & & 100 \\
\hline
\end{tabular}




\subsection{Corrosion behavior}

Figure 9 shows SEM micrographs of BM samples in different HT states after immersion in $3.5 \% \mathrm{NaCl}$ solution for 360 hours. Micrograph of BM-O shows small completely formed pits. Micrograph of BM-T4 shows homogenous corrosion behavior all over the sample surface with a uniform oxide layer. Moreover, the BM-T4 samples showed regularly distributed pits initiation cites. Hence, it can be seen that the BM in T4 temper was subjected to general corrosion and homogenous pitting corrosion. Micrograph of BM-T6 sample shows a great susceptibility to localized pitting corrosion as a result of the formation of large and deep pits, in the thin oxide layer formed.

Figure 10 shows the NZ SEM micrographs of all FS welded samples after immersion in 3.5\% $\mathrm{NaCl}$ solution for 360 hours. For samples 1, 2, and 3 (left in the AW state), the samples are subjected to localized pitting corrosion. Severity of the pitting corrosion can be evaluated through the frequency of pits in the given area, and its size. Samples also showed oxide film pits cracking (pitting initiation). Samples 1, and showed nearly the same pits cracks frequency and size, while sample 3 showed less pits cracks frequency. For samples 4, 5, and 6 (PWH treated to T4 state), sample 4 showed a severely deteriorated oxide film with multiple and random crack cites. While, sample 5 showed a more uniform thin oxide film with high frequency of small pits formation. Sample 6 showed a more desirable formation of oxide film with relatively thicker film and an immature pits initiation, it also showed ability to reform oxide film on the pits locations. Upon these samples, sample 6 showed the best corrosion behavior. For samples 7, 8, and 9 (PWH treated to T6 state), sample 7 showed micro cracks across the oxide film. While sample 8 showed a partially formed thinner oxide film. A large pitting initiation cites was found in the thinner film. Sample 9 showed the most preferable film formation with homogenous corrosion pits and presence of shallow cracks in an over formed oxide layer. For all samples, it can be observed that pitting initiation cites are having correlation with cites of intermetallic precipitates and greatly affected by their distribution and size. Such observation was also observed by Mosleh et al.[12], Alsamuraee et al.[18], and Bousquet et al.[19]. This observation suggests the formation of corrosion cells where the precipitates, of less Ecorr, acts as a sacrificial anode to the Al matrix, of higher Ecorr. EDX microanalysis spectra recorded in cites 1, 2, and 3 at Figure 10 (2), is shown at Figure 11.

Comparing FS welded samples with BM samples of the same HT, it can be seen that FSW of samples originally annealed and samples PWHT to T6 temper, have decreased pitting corrosion susceptibility as compared to BM-O and BM-T6. But, For T4 PWHT, FSW have increased pitting corrosion susceptibility.

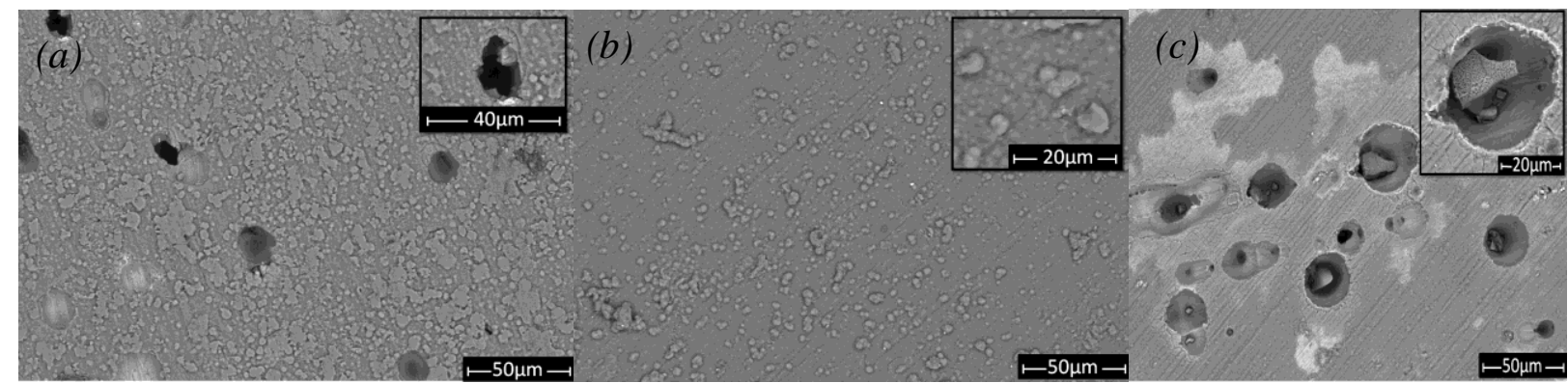

Figure 9: SEM micrographs of BM samples in (a) $O$ temper, (b) T4 temper, and (c) T6 temper, after immersion in $3.5 \% \mathrm{NaCl}$ solution for 360 hours. 


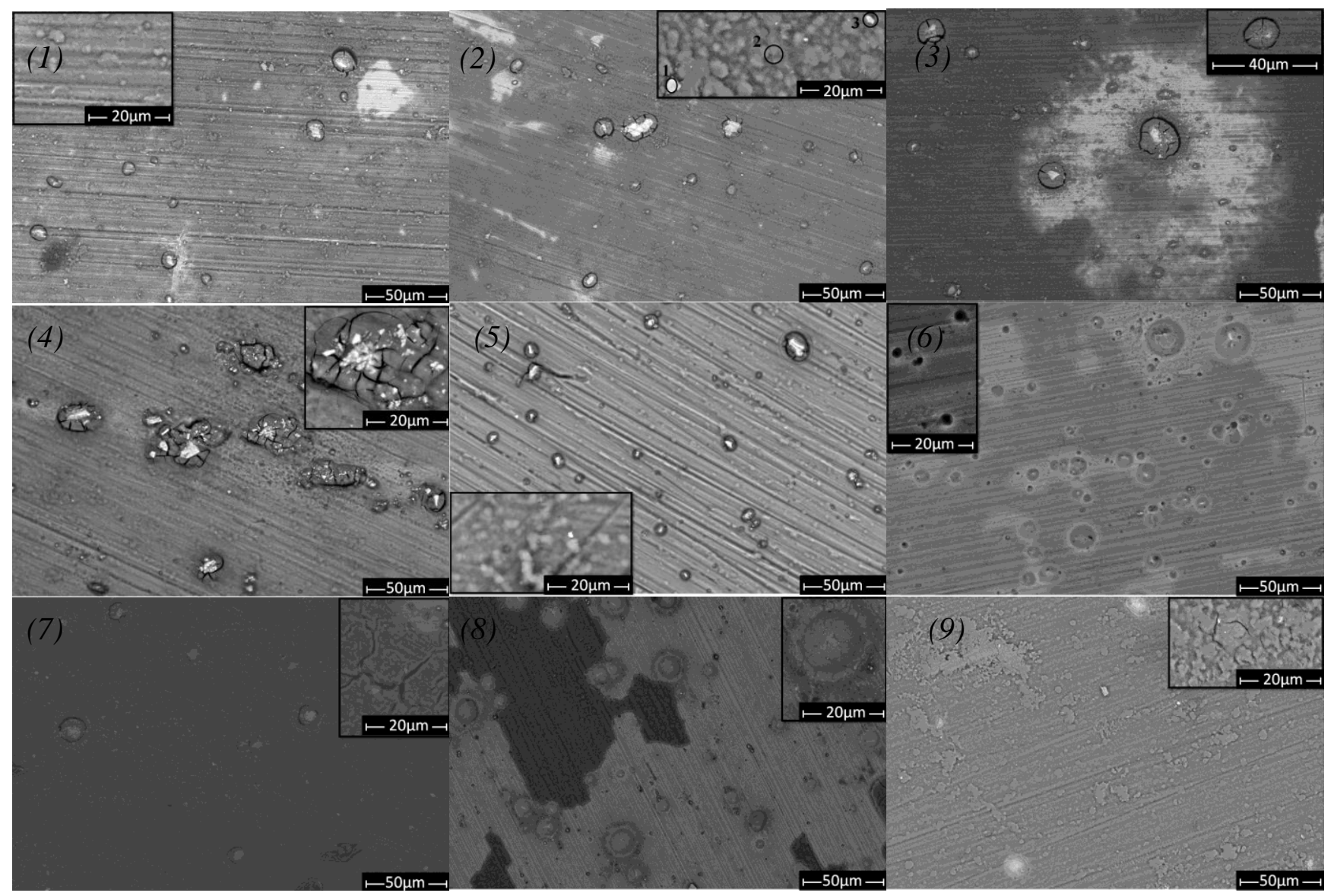

Figure 10: SEM micrographs of samples' NZs, FS welded and PWHT with conditions listed in Table 3 , after immersion in $3.5 \% \mathrm{NaCl}$ solution for 360 hours.

EDX microanalyses at cites 1 and 3 where bright spots are apparent in the SEM micrographs have showed high weight percentages of $\mathrm{Zn}(2.69,3.09)$ and $\mathrm{Mg}(0.85,1.03)$ which suggests the formation of intermetallic precipitates of $\left(\mathrm{Mg}_{\mathrm{x}} \mathrm{Zn}_{\mathrm{y}}\right)$ and/or $\left(\mathrm{Al}_{\mathrm{x}} \mathrm{Zn}_{\mathrm{y}} \mathrm{Mg}_{\mathrm{z}}\right)$ at these locations[12, 26]. EDX microanalyses at cite 2 where dark oxide film is believed to be formed as a result of sample surface corrosion, showed absence of the alloying elements. Hence, it can be deduced that at such regions only $\mathrm{Al}_{2} \mathrm{O}_{3}$ compounds are present. In all EDX microanalyses cites, elements such as $\mathrm{C}, \mathrm{Si}$, and $\mathrm{Na}$ which are not part of the $\mathrm{BM}$ composition where present. Presence of Si and $\mathrm{C}$ may be resulted from the grinding process with $\mathrm{SiC}$ papers prior to the immersion. While Na residuals presence may be resulted from the immersion solution. Presence of such elements suggests improper cleaning process before and after immersion despite the use of the ultrasonic vibrator.

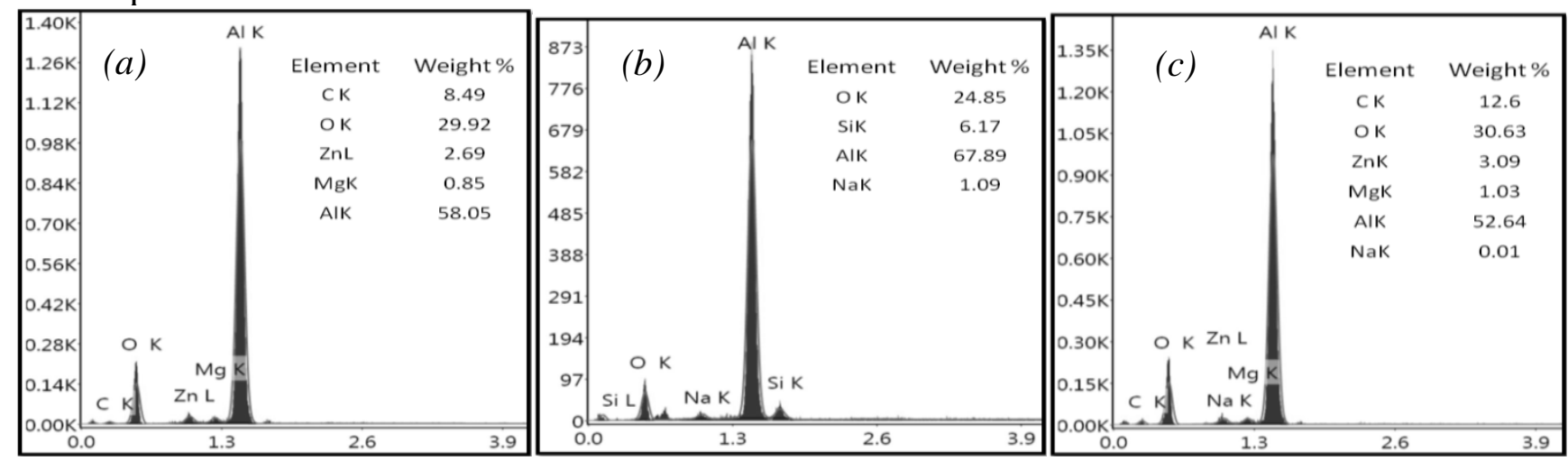

Figure 11: EDX spectra and content (in wt. \%) of different elements recorded at cites (a) 1, (b) 2, and (c) 3 (shown in Figure $10(2))$. 
Potentiodynamic polarization plot of all samples in $3.5 \% \mathrm{NaCl}$ solution is shown in Figure 12 . By sweeping the potential applied on the samples, the current density of the sample changes forming the two branches of the Tafel plot. At the cathodic branch, $i_{\text {corr }}$ drops as the potential increase. This is accompanied with hydrogen evolution and oxygen reduction at the intermetallic cathodes as:

$$
\begin{aligned}
& 2 \mathrm{H}^{+}+2 e^{-} \rightarrow \mathrm{H}_{2} \\
& \mathrm{O}_{2}+2 \mathrm{H}_{2} \mathrm{O}+4 e^{-} \rightarrow 4 \mathrm{OH}
\end{aligned}
$$

This drop continues till the potential applied reaches the Ecorr of the sample. Where the cathodic process normally slows down, the anodic oxidation of the metal is accelerated by anodic polarization. Beyond the Ecorr, at the anodic branch, the current density starts to increase indicating the presence of the corrosion attack which follows the following reactions:

$$
\begin{aligned}
& \mathrm{Al} \rightarrow \mathrm{Al}^{+3}+3 \mathrm{e}^{-} \\
& \mathrm{Al}^{+3}+3 \mathrm{H}_{2} \mathrm{O} \rightarrow \mathrm{Al}(\mathrm{OH})_{3}+3 \mathrm{H}^{+}
\end{aligned}
$$

Accordingly, a protective oxide film starts to cover the surface of the sample as a result of corrosion reactions. When the surface of sample is entirely covered with the oxide film, a passivation region is developed in the Tafel plot characterized by constant or slowly increasing current density where corrosion attack ceases. Aggressive chloride ions start to attack the oxide film weakest points. Full or partial recovery of the oxide layer occurs until the breakdown potential (Ebd) is reached and sustained dissolution by pitting occurs due to insufficient rate of repassivation [28]. Pits propagate through the sample's surface. According to the anodic reactions mentioned above, the $\mathrm{pH}$ of the solution will decrease as pitting propagates. To balance the positive charge produced by reactions 3and 4, chloride ions will migrate into the pit. The resulting $\mathrm{HCl}$ formation inside the pit causes accelerated pit propagation[18]. Also, galvanic cell corrosion between oxide film covered surfaces and uncovered pits surface, helps in the acceleration of the corrosion. As a result, current density increases rapidly through anodic dissolution stage. This severe attack results in the formation of another oxide layer, resulting in the formation of a transpassive region at higher potential values.

All samples subjected to the Potentiodynamic test have shown typically all the regions discussed above except for the Tafel plot of BM-T6 samples where passivation didn't appear to be happened. This can be as a result of severe corrosion attack at which the sample's surface was not able to hold a solid oxide layer or repassivate.

The Tafel slopes extracted from the Tafel plots are listed in . Where as, Figure 13 show the values of Ecorr.

The tendency of different heat treated BMs samples to corrode can be assessed by the value of the Ecorr. A less negative corrossion potential indicates tendance of the sample to nobility. In cotrast to this, when the Ecorr shifts to more negative values, this indicates the tendency of sample to be corroded. Upon all heat treated BMs, BM-T6 showed the least negative Ecorr, follwed by BM-O and BM-T4. As compared to BM samples, and except for the T6 samples, FSW have decreased the samples tendency to corrode. This may be attributed to the change of the grain structure from rolled elongated grains to equiaxial grains. For the T6 PWHT samples, BM-T6 is having a lower tendency to corrode than that of FSW. However this can't be disscussed away from the fact that BM-T6 didn't show a passivation region. 
EFFECT OF FRICTION STIR WELDING PARAMETERS ON MICROSTRUCTURAL CHARACTERISTICS AND CORROSION BEHAVIOR OF AA7020-O BASED ON TAGUCHI DOE APPROACH
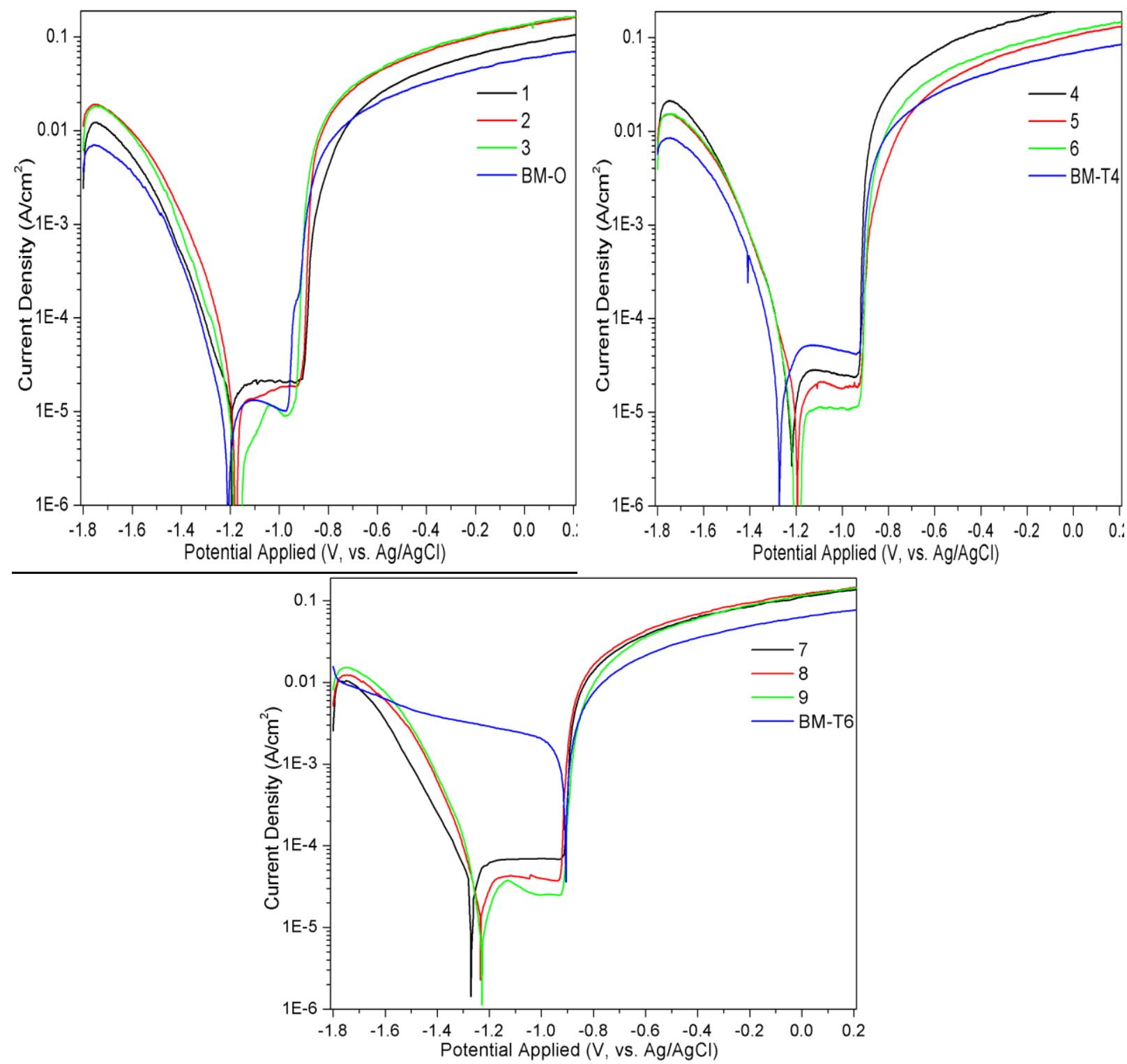

Figure 12: Potentiodynamic polarization plot for $B M$ as a function of HT, and for NZs of samples FS welded and PWHT with conditions listed in Table 3 in $3.5 \% \mathrm{NaCl}$ solution

Table 6: Electrochemical corrosion parameters estimated from Tafel plots

\begin{tabular}{|c|c|c|c|c|c|}
\hline $\begin{array}{c}\text { Sample } \\
\text { Code }\end{array}$ & $\begin{array}{c}\beta_{\mathrm{a}} \\
(\mathrm{V} / \mathrm{dec})\end{array}$ & $\begin{array}{c}\beta_{\mathrm{c}} \\
(-\mathrm{V} / \mathrm{dec})\end{array}$ & $\begin{array}{c}\text { Ecorr } \\
(\mathrm{V}, \mathrm{vs} . \mathrm{Ag} / \mathrm{AgCl})\end{array}$ & $\begin{array}{c}\text { Icorr } \\
\left(\mu \mathrm{A} / \mathrm{cm}^{2}\right)\end{array}$ & $\begin{array}{c}\mathrm{CR} \\
(\mathrm{mm} / \mathrm{yr})\end{array}$ \\
\hline BM-O & 0.2641 & 0.183 & -1.2088 & 4.91 & 0.05323 \\
\hline BM-T4 & 0.4473 & 0.2203 & -1.2718 & 55.454 & 0.60114 \\
\hline BM-T6 & 0.1809 & 0.0452 & -0.907 & 652.65 & 7.07499 \\
\hline 1 & 0.094 & 1.291 & -1.196 & 15.202 & 0.1648 \\
\hline 2 & 0.113 & 1.323 & -1.177 & 11.406 & 0.12365 \\
\hline 3 & 0.533 & 0.162 & -1.172 & 2.1191 & 0.02297 \\
\hline 4 & 0.121 & 0.182 & -1.218 & 22.165 & 0.24028 \\
\hline 5 & 0.117 & 0.948 & -1.195 & 12.639 & 0.13701 \\
\hline 6 & 0.126 & 0.707 & -1.193 & 8.176 & 0.08863 \\
\hline 7 & 0.099 & 2.897 & -1.274 & 48.269 & 0.52326 \\
\hline 8 & 0.1371 & 0.1345 & -1.234 & 34.889 & 0.37821 \\
\hline 9 & 0.1325 & 0.1174 & -1.229 & 17.094 & 0.18531 \\
\hline
\end{tabular}


Figure 14 shows the main effects on Ecorr of the NZ. It can be seen that, increasing the tool rotational speed results in an increase of Ecorr in the less negative (nobility) direction. While, the Ecorr is having an inversely proportional relation with the welding speed and it can be shown that it has a minor effect. However, changing the material state, after FSW, from the AW state to T4 temper or T6 temper is having a major inverse effect on the Ecorr. This may be attributed to the change in the grains structure and precipitates states. For samples 1, 2, and 3 , the low density small precipitates decrease the corrosion tendency. As the precipitates density and size increase, in samples 4,5 , and 6 the corrosion tendency increase. Also for samples 7, 8, and 9, coarse precipitates and its dispersion all over the sample's surface lead to an increase in the corrosion tendency.

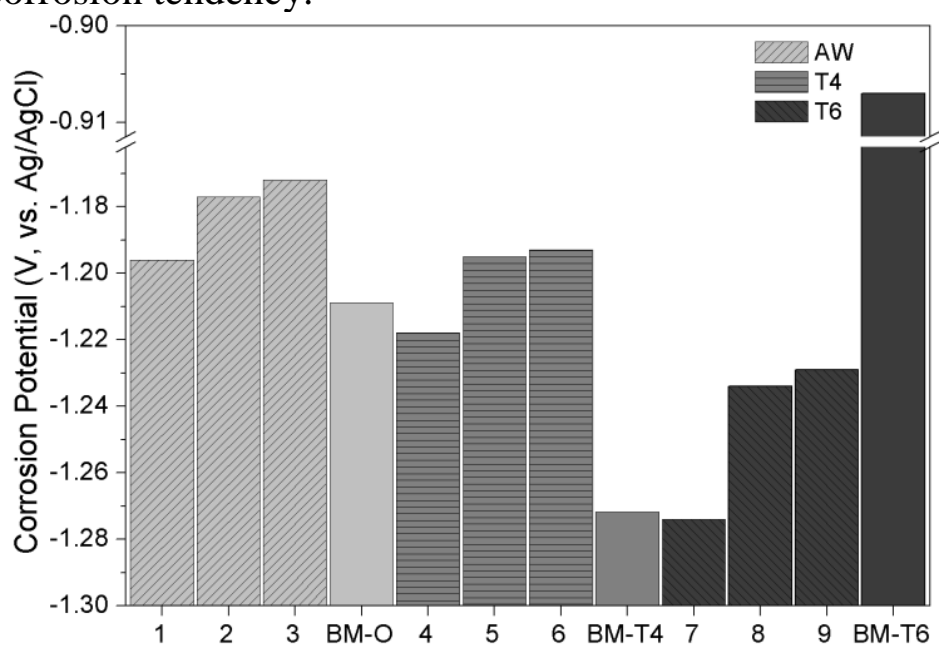

Figure 13: $E_{\text {corr }}$ of BM with different HTs and at the NZ of samples FS welded and PWHT with conditions listed in Table 3 in $3.5 \% \mathrm{NaCl}$ solution.

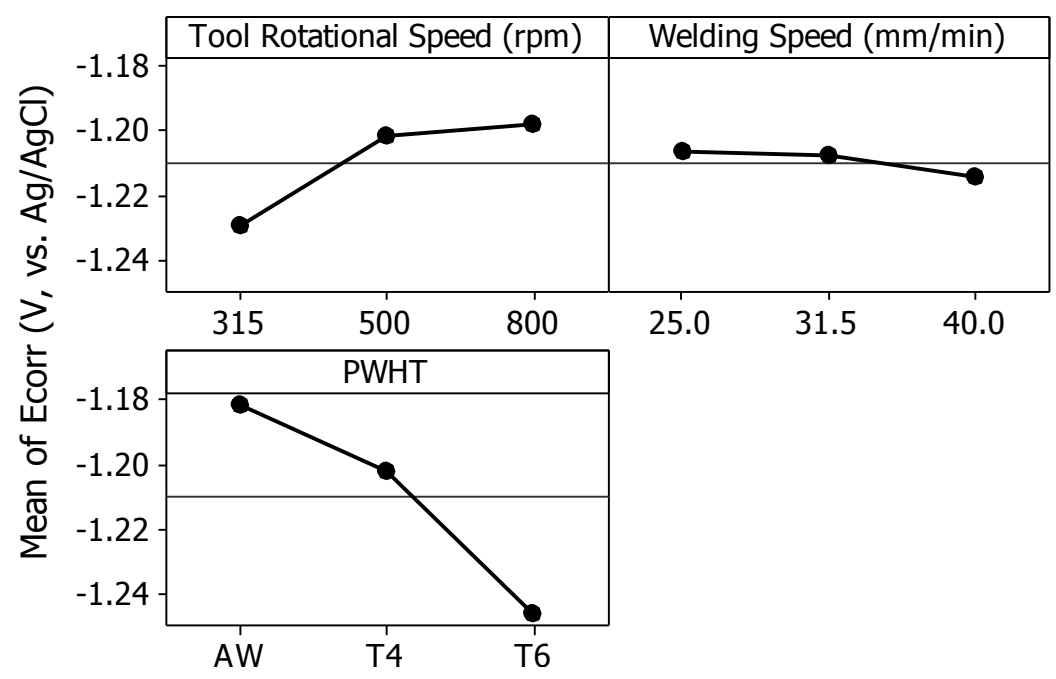

Figure 14: Plot of factors effects on Ecorr of the NZs

Table 7: The ANOVA results for Ecorr of the NZs

\begin{tabular}{|l|c|c|c|c|c|c|}
\hline Source & DOF & SS & MS & F & P & $\mathrm{P}_{\mathrm{C}}(\%)$ \\
\hline Tool Rotational Speed (rpm) & 2 & 0.0017 & 0.0009 & 25.58 & 0.038 & 20.92 \\
\hline Welding Speed (mm/min) & 2 & 0.0001 & 0.0001 & 1.62 & 0.382 & 1.32 \\
\hline PWHT & 2 & 0.0064 & 0.0032 & 94.05 & 0.011 & 76.94 \\
\hline Residual Error & 2 & 0.0001 & 0.0000 & & & 0.82 \\
\hline Total & 8 & 0.0083 & & & & 100 \\
\hline
\end{tabular}


It can be seen from the ANOVA results listed in Table 7 that the tool rotational speed $(\mathrm{P}=0.038)$, and the PWHT $(\mathrm{P}=0.011)$ are the statistically significant affecting factors on the Ecorr.

Where, the PWHT has the most significant impact on Ecorr followed by the tool rotational speed. In addition, the effect of welding speed $(\mathrm{P}=0.382)$ is not statistically significant. PWHT has the higher $\mathrm{P}_{\mathrm{C}}$ of $76.94 \%$ followed by that of the tools rotational speed $20.92 \%$ while the welding speed has the least $\mathrm{P}_{\mathrm{C}}$ of $1.32 \%$.

Using Tafel plot extrapolation, $i_{\text {corr }}$ was obtained. $C R$, in terms of penetration rate $(\mathrm{mm} / \mathrm{yr})$, was calculated using Faraday's law as follows:

$$
C R=3.27 \times 10^{-3} E W \frac{i_{\text {corr }}}{\rho}
$$

Were $\rho$ is the material density, for AA7020 the density $=2.78 \mathrm{~g} / \mathrm{cm}^{3}, \mathrm{EW}$ is the equivalent weight of the material. The EW is a function in the valence, atomic weight, and mass fraction of elements having more than $1 \%$ atomic weight. Using atomic weight percentage listed in Table 1, the EW for the alloy in the present study is 9.216 [29-31]. Accordingly, CR is calculated and shown in Figure 15. CR for BM-O is the least upon all other BM with HTs of T4 or T6. Also, except for sample 3, CR of BM-O is less than that of all originally annealed samples, FS welded, and left in the AW condition. On the other hand, BM in HT states of T4 and T6 are having a higher CR than that of FS welded samples and PWHT to the respective state. As a result, it can be concluded that FSW and PWHT have improved the CR of AA7020. Also, for higher tool rotational speeds than that in this study, CR of PWH treated samples can be of lowers values. Figure 16 shows the main effects on Ecorr of the NZ. It can be seen that, increasing the tool rotational speed results in a decrease of the CR. While, the $\mathrm{CR}$ is having an inversely proportional relation with the welding speed and it can be shown that it has a minor effect. However, changing the material state, after welding process, from the AW state to T4 temper or T6 temper is having a major direct effect on the CR. The relation between PWHT and CR can be attributed to the type of corrosion. Based on what is shown in Figure 10, it can be deduced that the predominant corrosion attack in all samples' surfaces is the localized pitting corrosion. For AA2024-T3, Bousquet et al.[19] have shown that corrosion severity depends on size and density of intermetallics and on intergranular precipitation. Coarse precipitates of high density increase the galvanic corrosion, and hence, the CR. Accordingly, and based on what have been observed in Figure 5, PWH treating samples to T4 temper has increased the precipitates size and density compared to the AW condition, which resulted in a higher CR. Also, PWH treating samples to T6 temper have further increased the size of precipitates. This has resulted in the highest CR of all FS welded samples.

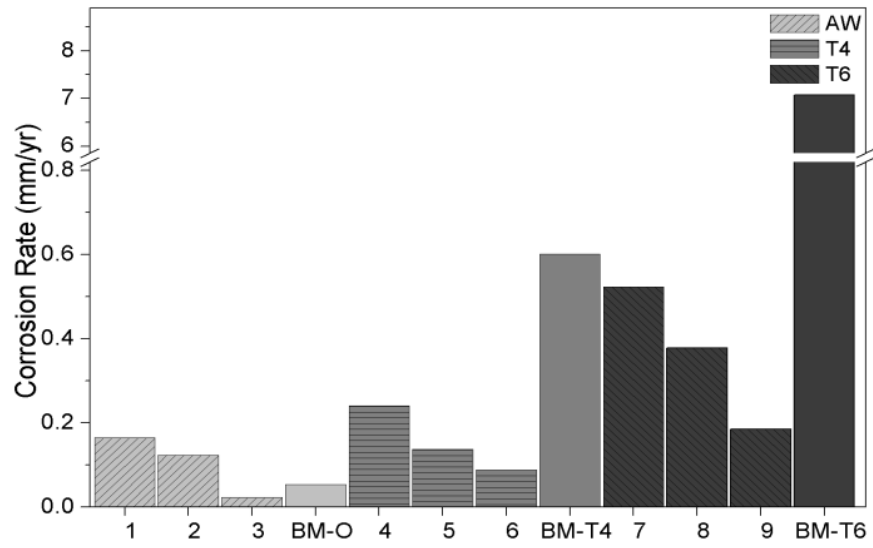

Figure 15: CR of BM with different HTs and at the NZ of samples FS welded and PWHT with conditions listed in Table 3 in $3.5 \% \mathrm{NaCl}$ solution.

The relation between tool rotational speed and CR can be attributed to the effect of tool rotation on the precipitates size and distribution. As observed in Figure 5, increasing the tool rotational speed decreased the size and density of the precipitates and tended to agglomerate it. This in turn reduces the galvanic corrosion effect and hence decreases the CR. The relative 
velocity between the tool and the material during FSW is influenced mainly by the rotational speed $[3,32]$. This can explain the minor effect of the welding speed.

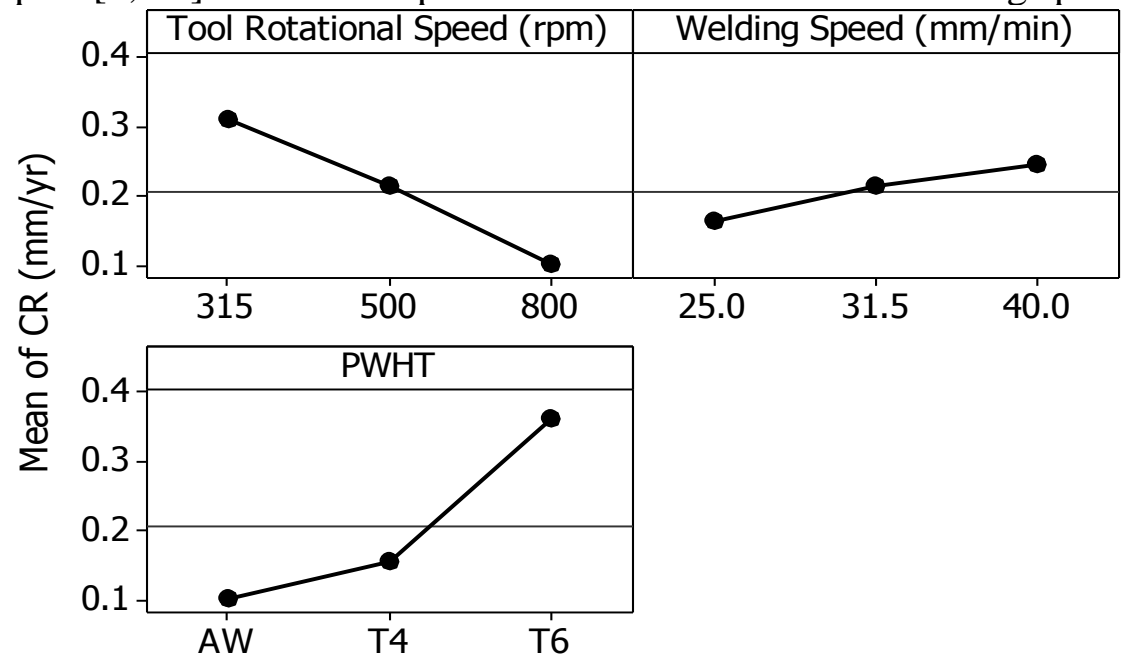

Figure 16: Plot of factors effects on CR of the NZs.

Table 8: The ANOVA results for CR of the NZs

\begin{tabular}{|l|c|c|c|c|c|c|}
\hline Source & DOF & SS & MS & F & P & $\mathrm{P}_{\mathrm{C}}(\%)$ \\
\hline Tool Rotational Speed (rpm) & 2 & 0.0666 & 0.0333 & 21.87 & 0.044 & 34.62 \\
\hline Welding Speed (mm/min) & 2 & 0.0105 & 0.0052 & 3.44 & 0.225 & 5.45 \\
\hline PWHT & 2 & 0.1123 & 0.0561 & 36.86 & 0.026 & 58.35 \\
\hline Residual Error & 2 & 0.0030 & 0.0015 & & & 1.58 \\
\hline Total & 8 & 0.1924 & & & & 100 \\
\hline
\end{tabular}

It can be seen from the ANOVA results listed in Table 8 that the tool rotational speed $(\mathrm{P}=0.044)$, and the PWHT $(\mathrm{P}=0.026)$ are the statistically significant affecting factors on the $\mathrm{CR}$. Where, the PWHT has the most significant impact on CR followed by the tool rotational speed. In addition, the effect of welding speed $(\mathrm{P}=0.225)$ is not statistically significant. PWHT has the higher $\mathrm{P}_{\mathrm{C}}$ of $58.35 \%$ followed by that of the he tool rotational speed $34.62 \%$ while the welding speed has the least $\mathrm{P}_{\mathrm{C}}$ of $5.45 \%$.

\section{CONCLUSION}

Based on the present investigation results, main conclusions drawn are as follows:

1. HT of AA7020 Al alloy BM did not affect the rolled extremely elongated structure of the $\alpha$-Al matrix, while, it has greatly affected the size and distribution of intermetallic and intergranular precipitates.

2. For all BM tempers, the grain boundaries could not be resolved and it was not possible to determine the GS of the extremely elongated grains due to the banded structure resulted from the rolling operation.

3. Based on SEM micrographs, HT is greatly affecting the corrosion behavior of the BM. T4 temper has decreased the BM susceptibility to pitting corrosion as compared to $\mathrm{O}$ state, while T6 temper has greatly increased it.

4. Upon all heat treated BMs, BM-T6 showed the least negative Ecorr, followed by BM-O and BM-T4, while, CR of BM-O is the least upon all heat treated BMs followed by BM$\mathrm{T} 4$ and BM-T6, in an ascending order.

5. As compared to BM samples, and except for the T6 PWH treated samples, FSW have decreased the samples tendency to corrode (Ecorr). Also for T4 and T6 tempers, FSW has highly decreased the CR in the NZ, while it is of comparable values in the case of AW state.

6. PWHT has clearly affected the precipitates density in the NZ, AW samples had the least density followed by T4 and T6 tempers in an ascending order. Also, it has clearly affected 
the precipitates size in the NZ. T6 tempered samples have the coarsest precipitates size followed by T4 and AW states.

7. Increasing the tool rotational speed tends to have a refining and agglomerating effect on the size and distribution of precipitates in the NZ.

8. There is not enough evidence on the effect of welding speed on the precipitates size and density in the NZ.

9. Based on ANOVA results, tool rotational speed is statistically significant affecting factor on the GS, grains' AR, Ecorr, and CR in the NZ with a direct PC of $48.83 \%$, direct PC of $74.85 \%$, direct PC of $20.92 \%$, and inverse PC of $34.62 \%$ respectively.

10. Based on ANOVA results, changing the FS welded samples states form AW to T4 or T6 is statistically significant affecting the GS, Ecorr, and CR in the NZ with a direct PC of $41.11 \%$, an inverse PC of $76.94 \%$, and a direct PC of $58.35 \%$, while it is not significantly affecting the grains' AR.

11. Based on ANOVA results, welding speed is not statistically significant affecting factor on the GS, Ecorr, and CR, while it is significantly affecting the grains' AR with an inverse PC of $22.87 \%$.

12. The study illustrates that the application of statistical analysis coupled with Taguchi DOE approach is simple, effective, and efficient in developing relations and determining the significance of control factors on the GS characteristics and corrosion behavior of FSW joints with the least number of trials.

\section{REFERENCES}

[1] R. S. Mishra and Z. Y. Ma, "Friction stir welding and processing," Mater. Sci. Eng. R Reports, vol. 50, no. 1-2, pp. 1-78, 2005.

[2] a. C. Muñoz, G. Rückert, B. Huneau, X. Sauvage, and S. Marya, "Comparison of TIG welded and friction stir welded Al-4.5Mg-0.26Sc alloy," J. Mater. Process. Technol., vol. 197, no. 1-3, pp. 337-343, 2008.

[3] A. S. Golezani, R. V. Barenji, A. Heidarzadeh, and H. Pouraliakbar, "Elucidating of tool rotational speed in friction stir welding of 7020-T6 aluminum alloy," Int. J. Adv. Manuf. Technol., vol. 81, no. 5-8, pp. 1155-1164, Nov. 2015.

[4] A. Rahimzadeh Ilkhichi, R. Soufi, G. Hussain, R. Vatankhah Barenji, and A. Heidarzadeh, "Establishing Mathematical Models to Predict Grain Size and Hardness of the Friction Stir-Welded AA 7020 Aluminum Alloy Joints," Metall. Mater. Trans. B Process Metall. Mater. Process. Sci., vol. 46, no. 1, pp. 357-365, 2014.

[5] C. a. W. Olea, L. Roldo, T. R. Strohaecker, and J. F. dos Santos, "Friction stir welding of precipitate hardenabel aluminium alloys: a review," Weld. World, vol. 50, no. 11/12, pp. 78-87, 2006.

[6] M. Kadlec, R. Ruzek, and L. Novakova, "Mechanical behaviour of AA 7475 friction stir welds with the kissing bond defect," Int. J. Fatigue, vol. 74, pp. 7-19, 2015.

[7] K. Dudzik and M. Czechowski, "Stress Corrosion Cracking of 5083 and 7020 Aluminium Alloys Jointed by Friction Stir Welding," Solid State Phenom., vol. 165, pp. 37-42, Jun. 2010.

[8] A. C. on C. and A. Steels, ASM Metals Handbook: Volume 3. 1980.

[9] K. Dudzik, "Influence of Joining Method on Electrochemical Corrosion Properties of 7020 Aluminum Alloy Joints," Solid State Phenom., vol. 220-221, pp. 589-594, Jan. 2015.

[10] C. Vargel, Corrosion of Aluminium. Elsevier, 2004.

[11] F. Gharavi, K. A. Matori, R. Yunus, N. K. Othman, and F. Fadaeifard, "Corrosion behavior of Al6061 alloy weldment produced by friction stir welding process," J. Mater. Res. Technol., vol. 4, no. 3, pp. 314-322, 2014.

[12] A. Mosleh, F. Mahmoud, T. Mahmoud, and T. Khalifa, "Microstructure and static immersion corrosion behavior of AA7020-O Al plates joined by friction stir welding," J. Mater. Des. Appl., no. November 2015, p. 1464420715594484-, Jul. 2015.

[13] K. N. Krishnan, "The effect of post weld heat treatment on the properties of 6061 friction stir welded joints," J. Mater. Sci., vol. 37, no. 3, pp. 473-480, 2002.

[14] A. Sullivan and J. D. Robson, "Microstructural properties of friction stir welded and post-weld heat-treated 7449 aluminium alloy thick plate," Mater. Sci. Eng. A, vol. 478, 
[15] G. Rambabu, D. Balaji Naik, C. H. Venkata Rao, K. Srinivasa Rao, and G. Madhusudan Reddy, "Optimization of friction stir welding parameters for improved corrosion resistance of AA2219 aluminum alloy joints," Def. Technol., vol. 11, no. 4, pp. 330-337, 2015.

[16] M. Guillo and L. Dubourg, "Robotics and Computer-Integrated Manufacturing Impact $\&$ improvement of tool deviation in friction stir welding: Weld quality \& real-time compensation on an industrial robots," Robot. Comput. Integr. Manuf., vol. 39, pp. 2231, 2016.

[17] T. S. Mahmoud, A. M. Gaafer, and E. H. Mansour, "Microstructural and mechanical characteristics of AA7020-O Al plates joined by friction stir welding," Mater. Sci. Eng. A, vol. 527, no. 27-28, pp. 7424-7429, Oct. 2010.

[18] A. Alsamuraee, H. Ameen, and S. Al-Rubaiey, "Evaluation of the pitting corrosion for aluminum alloys 7020 in $3.5 \% \mathrm{NaCl}$ solution with range of temperature $(100-500){ }^{\circ} \mathrm{C}$," Am. J. Sci. Ind. Res., vol. 2, no. 2, pp. 283-296, 2011.

[19] E. Bousquet, A. Poulon-Quintin, M. Puiggali, O. Devos, and M. Touzet, "Relationship between microstructure, microhardness and corrosion sensitivity of an AA 2024-T3 friction stir welded joint," Corros. Sci., vol. 53, no. 9, pp. 3026-3034, 2011.

[20] O. Lorrain, V. Favier, H. Zahrouni, and D. Lawrjaniec, "Understanding the material flow path of friction stir welding process using unthreaded tools," J. Mater. Process. Technol., vol. 210, no. 4, pp. 603-609, 2010.

[21] ASM Handbook, chapter 4 "Heat treating,".vol. 4, 1991.

[22] G. K. Padhy, C. S. Wu, S. Gao, and L. Shi, "Local microstructure evolution in Al 6061-T6 friction stir weld nugget enhanced by ultrasonic vibration," Mater. Des., vol. 92, pp. 710-723, 2016.

[23] X. Wang, S. Mao, P. Chen, Y. Liu, J. Ning, H. Li, K. Zang, Z. Zhang, and X. Han, "Evolution of microstructure and mechanical properties of a dissimilar aluminium alloy weldment," JMADE, vol. 90, pp. 230-237, 2016.

[24] D. Cabibbo, M., Forcellese, A., Simoncini, M., Pieralisi, M., Ciccarelli, "Effect of welding motion and pre-/post annealing of friction stir welded AA5754 joints," Jmade, vol. 93, pp. 146-159, 2015.

[25] U. Prisco, A. Squillace, A. Astarita, and C. Velotti, "Influence of Welding Parameters and Post-weld Aging on Tensile Properties and Fracture Location of AA2139-T351 Friction-stir-welded Joints," Mater. Res. J. Mater., vol. 16, no. 5, pp. 1106-1112, 2013.

[26] M. K. Ismael, "Corrosion Resistance of Aluminum Alloy 7020-T6 in Sea Water," Eng. Tech. J., vol. 29, no. 8, pp. 1482-1490, 2011.

[27] F. E. T. Heakal, O. S. Shehata, and N. S. Tantawy, "Enhanced corrosion resistance of magnesium alloy AM60 by cerium(III) in chloride solution," Corros. Sci., vol. 56, pp. 86-95, 2012.

[28] F. El-Taib Heakal, N. S. Tantawy, and O. S. Shehata, "Impact of chloride and fluoride additions on surface reactivity and passivity of AM60 magnesium alloy in buffer solution," Corros. Sci., vol. 64, pp. 153-163, 2012.

[29] and S. J. K. Dean, S.W., Jr., W. D. France, Jr., Handbook on Corrosion Testing and Evaluation. New York: John Wiley, 1971.

[30] L. L. Shreir, R. a. Jarman, and G. T. Burstein, Corrosion: Volume 2 Corrosion Control. 2000.

[31] Astm G102, "ASTM G102-Standard practise for calculation of corrosion rates and related information from electrochemical measurements," vol. 89, no. Reapproved, pp. 416-422, 1994.

[32] R. NANDAN, T. DEBROY, and H. BHADESHIA, "Recent advances in friction-stir welding - Process, weldment structure and properties," Prog. Mater. Sci., vol. 53, no. 6, pp. 980-1023, 2008. 